\title{
Public consciousness and willingness to embrace ethical consumption of textile products in Mexico
}

\author{
Thalía Campos Deschamps, Bruce Carnie and Ningtao Mao*
}

\begin{abstract}
The Mexican economy has been showing a continuous and arguably remarkable growth in the last decade, and it is expected that this strong economic growth is based on a balance between social equity, fiscal growth and environmental protection. This composite situation requires us to have a clear understanding of changes in consumer behaviour and their attitudes towards ethical consumerism in this region.

With the use of a semi-structured questionnaire, this pilot study presented a detailed analysis of the consumer attitudes towards ethical consumerism in relation to their socioeconomic class levels in this region, the public consciousness and willingness to embrace ethical consumption of textile products in Mexico were thus determined. It is hoped that this knowledge provides the basis for the initiation of a framework of activities and measures to develop sustainable consumption habits and to educate consumers on the subject of ethical consumption.
\end{abstract}

Keywords: Ethical consumption, Textiles, Mexico, Public consciousness, Willingness

\section{Background}

Although certain trade agreements have been established with the aim to sustain a fair and balanced production, the popularity of fast fashion retailing has shown continual growth in both developed and developing countries. For example, North American Free Trade Agreement (NAFTA was implemented on January 1, 1994) is a trade agreement among the USA, Canada and Mexico that liberalizes restrictions on trade among the three countries. Under the NAFTA, US textile and apparel exporters benefit from duty-free entry on all qualifying products into Canada and Mexico, the two largest export markets for US textile and apparel products. These free trade agreements have manifest in a situation of providing a more fiscally sustainable situation for cotton farming in the USA while imports of cheap cotton and other textile goods to countries such as Mexico have boomed coinciding along with general increases in the economic growth in Mexico (see the Mexican-U.S. Free Trade Agreement, edited by Peter Garber, MIT Press, 1995). The economic growth in Mexico can in some part be attributed to raw cotton and other fibres being imported

\footnotetext{
* Correspondence: n.mao@leeds.ac.uk

School of Design, University of Leeds, Woodhouse Lane, Leeds LS2 9JT, UK
}

and subsequent local Mexican manufacturing taking place. This situation impacts favourably on the Mexican employment situation particularly in urban areas where significant garment manufacture is undertaken for both local consumption as well as subsequent export.

Developed countries have several formal textiles waste collecting systems and have been familiar with charity donations, thrift shops, vintage shops and not-for-profit shops for a number of years; these countries are where most of the significant fast fashion retailers have major presence. With the help of conscientious organizations and government support, companies such as Berohi S. Coop in Spain and Oxfam in the UK follow a sustainable cycle through the selling of used clothing and textiles that benefits the environment and society while avoiding the deployment of natural resources. Therefore, a textile recycling culture has been encouraged and an attempt to reduce the impact of mass consumption of textile products has been secured. The structure of these recycling companies is a clear and functional model to develop a recycling culture and help unprivileged communities at the same time in developing countries such as the cases of India, China, Indonesia and Guatemala and for the scope of this study, Mexico, which have been considered 
by multinational companies as emergent fast fashion market to exploit.

With these international fast fashion companies entering into Mexico to attract the Mexican consumer, it can be extrapolated from the situations found in the developed countries that, if Mexico does not develop a strategy to deal with the disposal of fast fashion products, several problems will arise in terms of waste accumulation from this type of fashion consumption. The strong and healthy economy growth in Mexico is based on a balance between social equity, economic growth and environmental protection, which require us to have a clear understanding of the consumer behaviour and their attitude towards ethical consumerism in the local region and to decide what measure is to be taken to educate consumers on these subjects.

In order to trigger ethical consumerism, it is important to identify the level of environmental consciousness at the time and the perceptions and opinions on this matter. It is also important to determine the line between awareness and willingness. The aim of this study is to investigate the consumer behaviour and their attitude towards pre-consumer and postconsumer textile waste recycling. Specific consumer group(s), that is either actively doing something or wanting to help but unaware of the options available and in place within specified cities and regions of Mexico, are identified, and whether they are aware the potential environmental issues caused by fast fashion and its subsequent disposal are determined. It is expected that ethical consumption patterns are established through the education of consumers to embrace the economical, social and cultural aspects of responsible and organized disposal of textile and clothing purchases and an approach to elongate the lifecycle of the garments.

The textile industry plays a key role in the economic development of Mexico and can be attributed to the significance that textiles play in generating employment. The current unemployment rate in Mexico stands at $3.9 \%$ of the population with a decrease of $0.6 \%$ from 2012 . The significance of the textile and related industries can also be characterised by the trade arrangements that exist between Mexico and the USA. This significant share is now at risk because of new trade agreements between US and China tariffs, making the later an important competitor for Mexico's textile industry. Additionally, the expiration of the Multi-Fibre Arrangement (MFA) in 2005 has the potential over time to dramatically change the international environment for the textile industry as a whole and for the Mexican industry in particular (Truett and Truett 2010).

Even though, Mexico has recently become known as an emerging economy with projects to upgrade seaports, railroads and telecommunications, among others, in order to improve the lifestyle of the citizens and also to change its reputation for drug violence. The World Business Council for Sustainable Development (WBCSD 2008) expects that by 2050, the GDP of Mexico, the second largest economy in Latin America, be projected to have outgrown that of the UK, currently the world's 6th largest economy (see Table 1).

According to the World Economic Forum Global Competitiveness Report 2012-2013, Mexico's effort to improve its business environment led to increase the potential to facilitate the development of entrepreneurial businesses. Other issues had been improved such as the transport infrastructure and the internal market size, among others, that have upgraded Mexico's situation to a competitive country with the opportunity to improve and reach the level of China or India. Even though, there are still some challenges that need to be covered in order to achieve the innovative potential, such as improvements in education, security, public institutions' management, lack of trust of politicians and low advance and implementation of new technology and innovation inside the industries to outgrowth productivity (Schwab and Sala-i-Martin 2012).

The environmental situation in Mexico is commonly known for issues such as its scarcity of hazardous waste disposal facilities; rural to urban migration; natural fresh water resources scarce and polluted in north, inaccessible and poor quality in centre and extreme southeast; serious air and water pollution in the national capital and urban centres along US-Mexico border; and land subsidence in Valley of Mexico caused by groundwater depletion, among others (Draggan and Saundry 2012). According to the Solid Waste Management Report from

Table 1 The economic growth in Latin America

\begin{tabular}{|c|c|c|c|c|c|c|c|c|c|}
\hline \multirow[t]{2}{*}{ Country } & \multicolumn{3}{|c|}{ Total GDP \% growth forecast } & \multicolumn{3}{|c|}{ Unemployment rate $\%$} & \multicolumn{3}{|c|}{ Consumer expenditure $\%$ growth } \\
\hline & 2012 & 2013 & 2014 & 2012 & 2013 & 2014 & 2012 & 2013 & 2014 \\
\hline Argentina & 5.6 & 4.2 & 4 & 9 & 8.5 & 8.4 & 7.1 & 4.7 & 4 \\
\hline Brazil & 3.4 & 3.6 & 4 & 6.7 & 6.7 & 6.7 & 5.4 & 5.1 & 5 \\
\hline Colombia & 3.8 & 4.5 & 4.5 & 11.5 & 11 & 10.5 & 6.5 & 5.5 & 5 \\
\hline Mexico & 0 & 2.9 & 3.8 & 4.5 & 3.9 & 3.5 & 3.6 & 3.5 & 3.9 \\
\hline
\end{tabular}


the Natural Resources and Environment Secretariat (SEMARNAT), textiles represent $1.4 \%$ of the total waste that ends up in the landfill. This report also notices that even though the urban solid waste volume that gets to be recycled has been incrementally increasing since $2005,4.8 \%$ of the total waste gets to be recycled, which is still a low percentage of the total. Furthermore, by 2011 , only $0.5 \%$ of the total textile waste was recycled (SEMARNAT 2012). This represents that around $3.152 \mathrm{t}$ of textile waste was saved at the final disposal landfill locations.

The disposed textiles accounts for $1 \%$ of the total MSW (see Fig. 1). Although the amount of municipal solid waste (MSW) recycled in the country is still low, it has increased in recent years. In 2011, $4.8 \%$ of the volume of MSW generated was recycled (see Fig. 2), and recycled textiles only accounts for $0.2 \%$ of the recycled wastes (SEMARNAT 2012) (see Fig. 2). In terms of informal waste management, for a long time, the recyclable picking process has been performed by garbage collectors from the lowest socioeconomic class that go directly to the disposition site itself, where they divide the waste in order to sell it to industrial companies that will give another use or life to the waste (Fig. 2) (Corral-Verdugo 1996).

Mexico's Government is now focusing upon establishing greener initiatives such as recycling along with other activities that will change the population's ecological culture. It is also a way of the government to communicate the objectives, strategies and high-impact actions to achieve the goal of a cleaner city by improving the interaction of the citizens with their environment while fostering a rational use of the natural resources, through changing the disposable habits among the population (SMA 2012b).

Different campaigns and initiatives have recently been developed to create a more conscious consideration by the residents of the city. Since last year, an itinerant exchange market (Mercado de Trueque) has been promoting an activity where the waste is collected and then sent

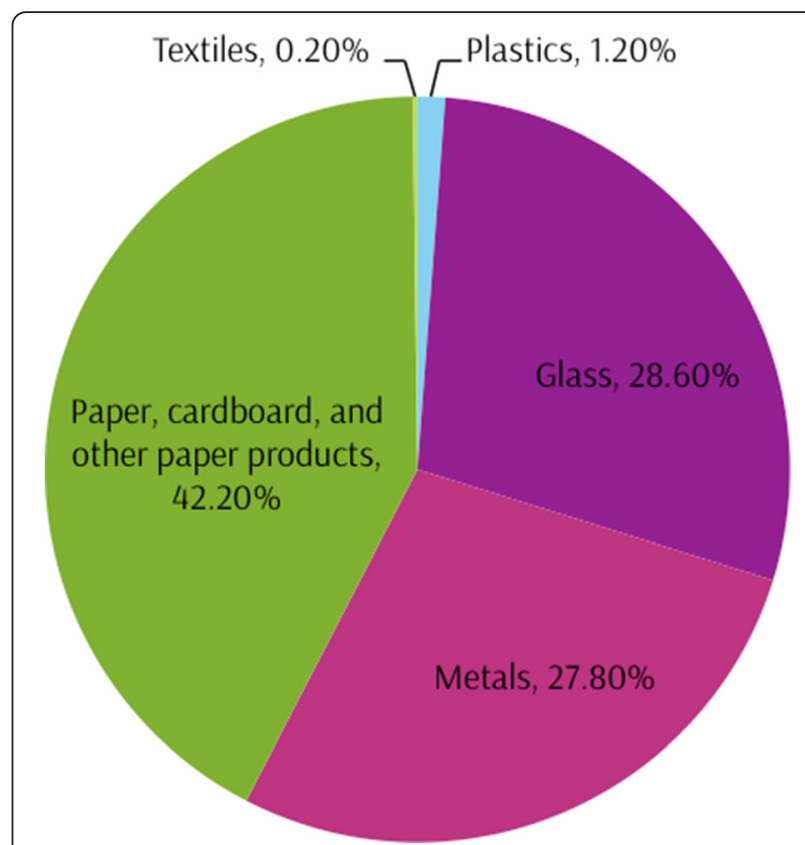

Fig. 2 Composition of the recycled municipal solid waste in Mexico, 2011 (SEMARNAT 2012)

to different companies specializing in recycling for reuse and, in return, the citizen receive green points which they can use to buy locally grown fresh food (SMA 2012a). These activities and initiatives arguably mean the continuity of the initiative to inculcate a culture of recycling and to develop environmental awareness regarding waste management concerns. Another sustainable approach that has been trying to tackle environmental damage and foster sustainable consumption is the 'Tu Ola' programme (see Fig. 3). This programme is based on the collection of points and rewards when people make use of the initiatives that the government and other involved organizations have been developing such as the use of bicycles, 'car pooling, the letting of environmental friendly cars, and by

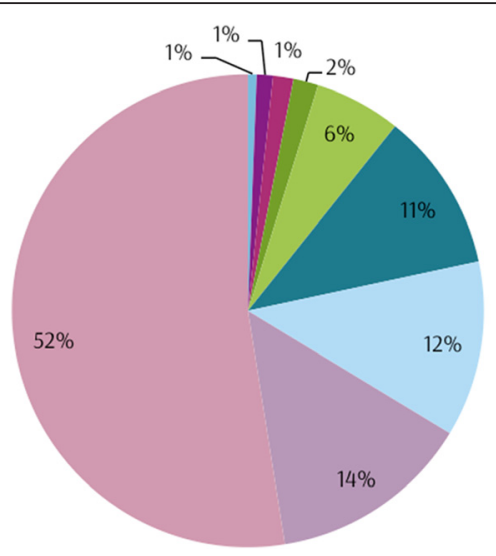

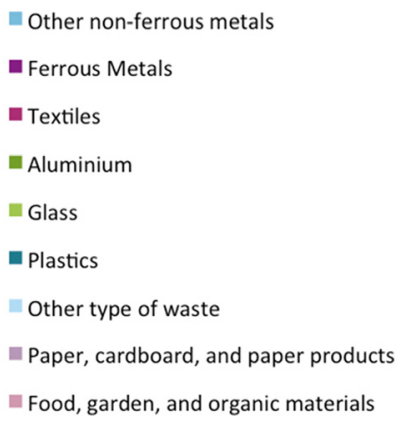

Fig. 1 Composition of the municipal solid waste in Mexico, 2011 (SEMARNAT 2012) 

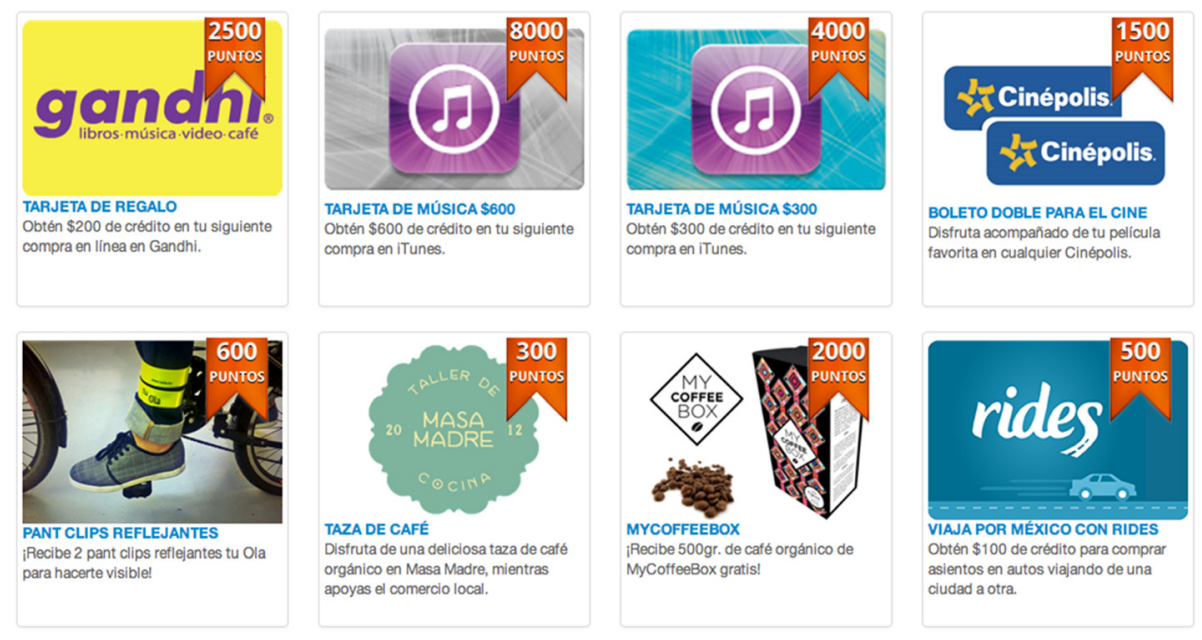

Fig. 3 Types of rewards in the 'Tu Ola' programme (Tu Ola, www.swagger.mx; Las Páginas Verdes (The Green Pages) 2012)

participating in the exchange market ( $\mathrm{Tu}$ Ola, www. swagger.mx). This collection of points is the first programme in Mexico that rewards you for green actions in your daily life. This exchange system was created given that people seem to collaborate and get involved in the matter when they perceive some form of benefit.

Given that the disposable income of the middle class is expected to grow, as how it happened in India and China, it is important to identify whether people understand the implications of their consumption habits and the need for a conscientious disposal of waste (Hawley in Gwilt and Rissanen 2011) and if they would embrace the textile recycling process.

Fast fashion has been around for a reasonable amount of time, and as a result, some areas of the world have developed programmes and infrastructures to help deal with the waste from the consumption of this industry. The forthcoming issue for the Mexican apparel market is the entrance of new multinational high-street brands such as H\&M, Forever 21 and GAP to the country as a result of the expiration of the MFA and the transitory custom tariffs in December 2011. These three companies established their first flagship store in Mexico City in late 2012, just in time for the Christmas season. They have made clear their intentions to expand inside the country in a short period of time. As a result of this, sales of apparel are expected to growth at big rates and with these successful rates other multinational companies would see an attractive market and begin to plan their entrance to Mexico and Latin America (Euromonitor 2013).

The entrance of these companies represents a significant increase in apparel consumption in terms of volume and frequency. By offering new trends more frequently than other retailers and by offering lower prices, fast fashion will change Mexicans consumption patterns and income expenditures in the next few years.
However, as an attitude of whole consumer society towards the ethical consumption of textile products, their awareness, consciousness and willingness of recycling and reusing textile products are unknown, and very few programme and initiative has been developed to deal with the management of textile waste in Mexico where fast fashion has had a much more recent impact on consumer habits. This therefore frames the problem for investigation by this study.

\section{Methods}

Ethical consumption is a central issue of this study. As both Littler (2009) and Humphery (2011) have noted, the term 'ethical consumption' does not refer to a clearly defined set of practices. For the purposes of this study, ethical consumerism can be defined as the practice of purchasing products and services produced in a way that minimizes social and/or environmental damage, while avoiding products and services deemed to have a negative impact on society or the environment. Both the environmental issues and societal issues will be addressed concurrently throughout the paper.

In order to address the environmental issues in relation to consumer societal status in the paper, a survey by using a semi-structured questionnaire (Additional file 1) was conducted to consumers within certain socioeconomic class levels, and the objectives of the survey are as follows:

- To identify the level of recycling culture of the targeted audience

- To recognize the level of awareness in the subject (sustainable consumption awareness)

- To understand customer behaviour with textile waste (disposal behaviours) 
- To determine customer opinions and perceptions on textile recycling and reusing (secondhand stores, charity, upcycling, etc.)

- To identify how willing the target audience is to collaborate with a socially and environmentally eco-ethically responsible brand of clothing

According to the AMAI, the number of electric bulbs of each household is used to define the respondent's socioeconomic class level according to the following numbers (see Table 2):

The socioeconomic level could be more accurately calculated when the number of bulbs is analysed along with other questions such as schooling and city or neighbourhood in which the respondent lives.

The total population in the country is $112,336,538$ people (INEGI 2013). From this number, about $76 \%$ of the people live in urban areas due to the fact that many Mexicans emigrate to the industrialized urban centres and the developing areas along the USA-Mexico border in a search for job opportunities. This implies that most of the people living in the main cities belong to the lower middle and low class (see Table 3 ).

As shown in Table 3, the C, D+ and D levels try to fulfil an easy and practical lifestyle with the basic services and conditions, meaning that this sector of the population will restrict their purchases to maintain their basic needs, such as food, clothing, a secure place to call home (walls) and health (services). A global common factor affecting the fashion consumption behaviour in Mexico is the appearance of new fast fashion retailers. People from the $\mathrm{C}$ and $\mathrm{D}+$ classes are keener to buy 'disposable fashion' because of the constant change in trends and styles and, majorly, because of the fact that the garments are cheaper and often with low quality, making them easy to discard once the trend has passed or the garment has torn.

This alluring consumption has been very popular within the teens and early twenties consumers and is predicted to continue in the short to medium term (Morgan and Birtwistle 2009). Because of the fact that more fast fashion retailers, such as $H \& M$ and Forever 21, are entering the Mexican market, there is an emerging need to trigger a sustainable consumption education among

Table 2 Average number of light bulbs in a house by social class (AMAl 2005)

\begin{tabular}{ll}
\hline Average number of light bulbs & Social class \\
\hline 16 or more & $A / B$ \\
Between 11 and 15 & $C+$ \\
Between 6 and 10 & $D+$ and $C$ \\
5 or less & $D$ and $E$ \\
\hline
\end{tabular}

the top classes and the middle classes who, eventually, will have the opportunity to purchase mass production low-quality products as the economy continues to improve.

Environmentally conscious consumers tend to be from the top two socioeconomic classes with at least a college degree at age 45 (Mattos 2012). This relationship of education with environmental awareness relies on the fact that highly educated people are more eager to understand the importance of the care of the environment and the environmental impact of their buying behaviours; therefore, they are more flexible to accept new methods of consumption (Mattos 2012). Therefore, a survey was designed and conducted to obtain the opinions from the $\mathrm{AB}, \mathrm{C}+$ and $\mathrm{C}$ socioeconomic classes, as outlined in Table 2 above, who spend around $4.7 \%$ of their disposable income in clothes and shoes (AMAI 2004).

A semi-structured questionnaire with multiple options and open-response questions was sent via e-mail and Facebook to Mexican citizens with access to a computer with Internet connection and with an active e-mail account. The structure of the questions was planned in order to get a precise classification in subjects such as demographics and consumption patterns. Some open responses were included to gain a deeper insight in respondent's environmental literacy and to highlight substantive statements (Gillham 2000).

This would lead the respondent from factual questions to opinions and beliefs through the behavioural responses that would help define which audience is more eager to participate with the project.

Some structured questions help define both the awareness of the subject and an audience's behaviour on the same subject to get an idea of the audience's opinions, intentions and actions. The examples of such questions include, identify the three main factors that you consider when buying new clothes; do you think of the consequences that your purchase will have on the environment when buying clothes?; have you ever purchased organic or eco-friendly clothing?; how much do you consider clothing companies contribute to environmental damage?; etc. The inclusion of 'other' category in the options shown for some of those questions would help as a catch-all to gain more insight into the consumers' behaviour. The variety of question/answer was necessary to maintain the respondent interested and gently guided to the end (Gillham 2000).

Additionally, a piloting test was made with marketing researchers who gave structure and opinion on questions that might need different options of answers or needed more explanation in order to get a valuable response and avoid misunderstandings or prevent an inferred reply, and there was also a piloting test with non-specialists in the 
Table 3 Socioeconomic class features (adapted from López Romo 2009)

\begin{tabular}{lllll}
\hline Socioeconomiclevel & Class & \% of total population & Education (average) & Main feature \\
\hline AB & Upper & 7.2 & University graduates and post-graduates & Planning and future \\
C+ & Upper Middle & 14 & University graduates & Fulfillment in entertaining and \\
& Middle & 17.9 & technology & Practical and easy lifestyle \\
C & Lower Middle & 35.8 & High school or secondary studies & Basic health conditions \\
D+ & Low & 18.3 & Secondary studies and incomplete elementary studies & Walls and some services \\
D & Lowest & 6.7 & Elementary studies & Nothing \\
E & & & Incomplete elementary studies
\end{tabular}

subject to avoid unfamiliar words or the use of jargon. Also, the following factors were considered for making the selection of survey samples based on the consumer social economical class levels:

1. Environmentally conscious consumers tend to be from the top two socioeconomic classes with at least a college degree at age 45 (Mattos 2012). This relationship of education with environmental awareness relies on the fact that highly educated people are more eager to understand the importance of the care of the environment and the environmental impact of their buying behaviours; therefore, they are more flexible to accept new methods of consumption (Mattos 2012). Therefore, the survey was designed and conducted to obtain the opinions from the $\mathrm{AB}, \mathrm{C}+$ and $\mathrm{C}$ socioeconomic classes, as outlined in Table 2, who spend around $4.7 \%$ of their disposable income in clothes and shoes (AMAI 2004). The classes of D+ and E will not be the focus of this study as these groups have been determined to be more focused on addressing their basic needs such as shelter, food and health care needs. Therefore, these groups would not have the disposable income to purchase fast fashion items of clothing.

2. In order to ensure that the respondents of the survey were from the classes identified as the focus of the study, questions were asked that related to the level of education attained. Questions were also asked about levels of lifestyle (including levels of health care and level of disposable income above $4 \%$ of total income) to differentiate between classifications $\mathrm{C}$ and $\mathrm{D}+$.

The influences of the number of sampling size on the reliability of the survey results of this research were considered. It is known that the sampling size depends on level of precision, confidence level and degree of variability. It is proved in the mathematics of probability that the size of the population is irrelevant unless the size of the sample exceeds a few percent of the total population you are examining, and also, the population size is only likely to be a factor when the survey is within a relatively small and known group of people. The more heterogeneous a population, the larger the sample size required to obtain a given level of precision. The less variable (more homogeneous) a population, the smaller the sample size (Miaoulis and Michener 1976).

There were 102 participants in this pilot study. This survey was active for 1 week during June 2013, and 160 copies of completed questionnaires were received; the subject descriptor questions generated a total sum of 102 effective respondents from both genders between the ages of 18 to 65 years old.

Although this may be regarded as a small sample, the degree of variability in terms of social economic status in this research are small, as the respondents are concentrated in three groups $\mathrm{A} / \mathrm{B}, \mathrm{C}+$ and $\mathrm{C} / \mathrm{D}+(77 \%$ of the respondents are from both $\mathrm{A} / \mathrm{B}$ and $\mathrm{C}+$ classes as shown in page 16) in the research; this could mean that the lower social economic classes in Mexico are much less interested in the ethical consumption of textile products. Therefore, the research conclusions are only suitable for the populations of middle social economic status in Mexico, and there should be no problem for this smaller number of sampling sizing with consideration of the extremely narrower distributions of the social economic status of the respondents in this research. In a summary, the conclusions concluded from this smaller sampling size of pilot study indicate that the targeted groups show a suitable degree of responsiveness to the areas of interest in the study to changing patterns of behaviour towards ethical consumption of textile goods. Given the results that this preliminary study reveals, there is some degree of evidence that an extension of the study to include a larger cohort of participant in the survey from the same classes of participants used for this pilot study may provide valuable results for the development of an ethically conscientious clothing brand to be established in Mexico City in the future. 


\section{Results and discussion}

The geographical distribution and socioeconomic status of the respondents

More than $60 \%$ of respondents are in the age range of 26 to 35 years old, and apparently, more than $40 \%$ are single people living alone or with their partner in free union. This data is consistent with the last population census held in 2010 by Instituto Nacional de Estadistica, Geografía e Informática (INEGI) where the percentage of married people was the lowest in all the country with $37.5 \%$ of the population in Mexico City being single and $14.2 \%$ living in free union.

The marital status is an event that is closely associated with age, for example, the proportion of young people who have decided to make a life as a couple is concentrated in the ages of 12-29; 74 of every 100 are single and in this same age range; 23 maintain a life partner and only two of every 100 are separated, divorced or widowed (INEGI 2013).

These changes in the common lifestyle are evidence that the original customs and habits of getting married young or the tradition of living with the parents until marriage have change as a result of higher economic power. This data directly reflects the declining birth rates by $9 \%$ showed from 2008 to 2012. Apparently, people are waiting longer to get married and have children. They are focusing more in their professional careers and quality of life before thinking about starting a family, and this number is expected to increase in the near future (Euromonitor 2013).

As more people are finding it easier and more convenient to live in free union and wait for children longer once they get married, the disposable income in Mexican houses would arguably be continuously increasing; hence, hedonistic and self-centred consumption would be the main concern for this share of the market in the following years.

In terms of employment, more than $80 \%$ of the respondents are either self-employed or employed in the public and private sector, with the later predominating. The rest of the respondents are still studying, and only $2 \%$ is unemployed while others are housewives and retirees.

It is evident in Fig. 4 that $60 \%$ of the respondents belong to the A/B social class (have 16 or more light bulbs in their household), while $38 \%$ belong to the $\mathrm{C} / \mathrm{C}+$ and D+ social class (have 6 to 15 light bulbs in a household) and $2 \%$ of respondents have 5 or less light bulbs living in a private room. This represents $79.1 \%$ of Mexican population, and the audience of this research range from lower middle class to upper class. Further analysis of the lives and conditions of their houses is needed for this $2 \%$ in order to avoid classifying them in the $\mathrm{E}$ social class given that it is the lowest; otherwise, their answers to this questionnaire would be discarded.

In terms of locations (see Fig. 5), 87 \% of the respondents live in Mexico City and the Metropolitan areas surrounding the capital city, where it has been recorded that $12 \%$ of the urban solid waste of all the country is generated (SEMARNAT 2012). It is the place where $21.4 \%$ of the total population of Mexico lives and where most of the C/D social classes are concentrated (INEGI 2013). In terms of municipalities, more than $54 \%$ of the respondents from Mexico City live in five of the boroughs (see Fig. 6) with a higher GDP per capita. This information, along with the number of light bulbs, is crucial to understand that the answers brought by the survey are mainly from a high/middle high class, with higher income

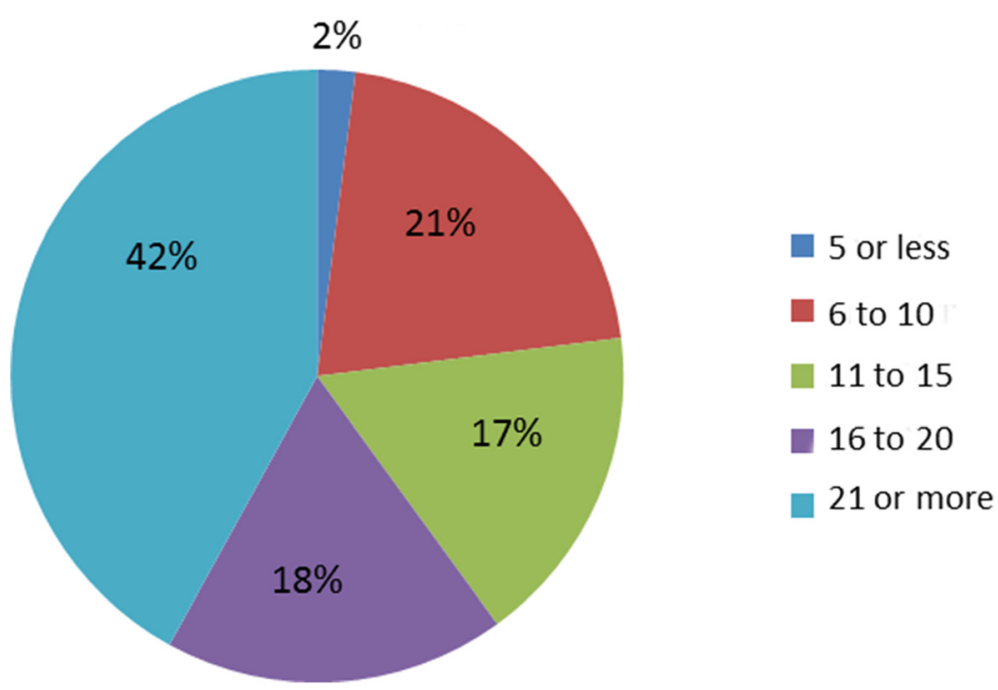

Fig. 4 The total number of light bulbs in a household including ceiling, walls and desk lamps 


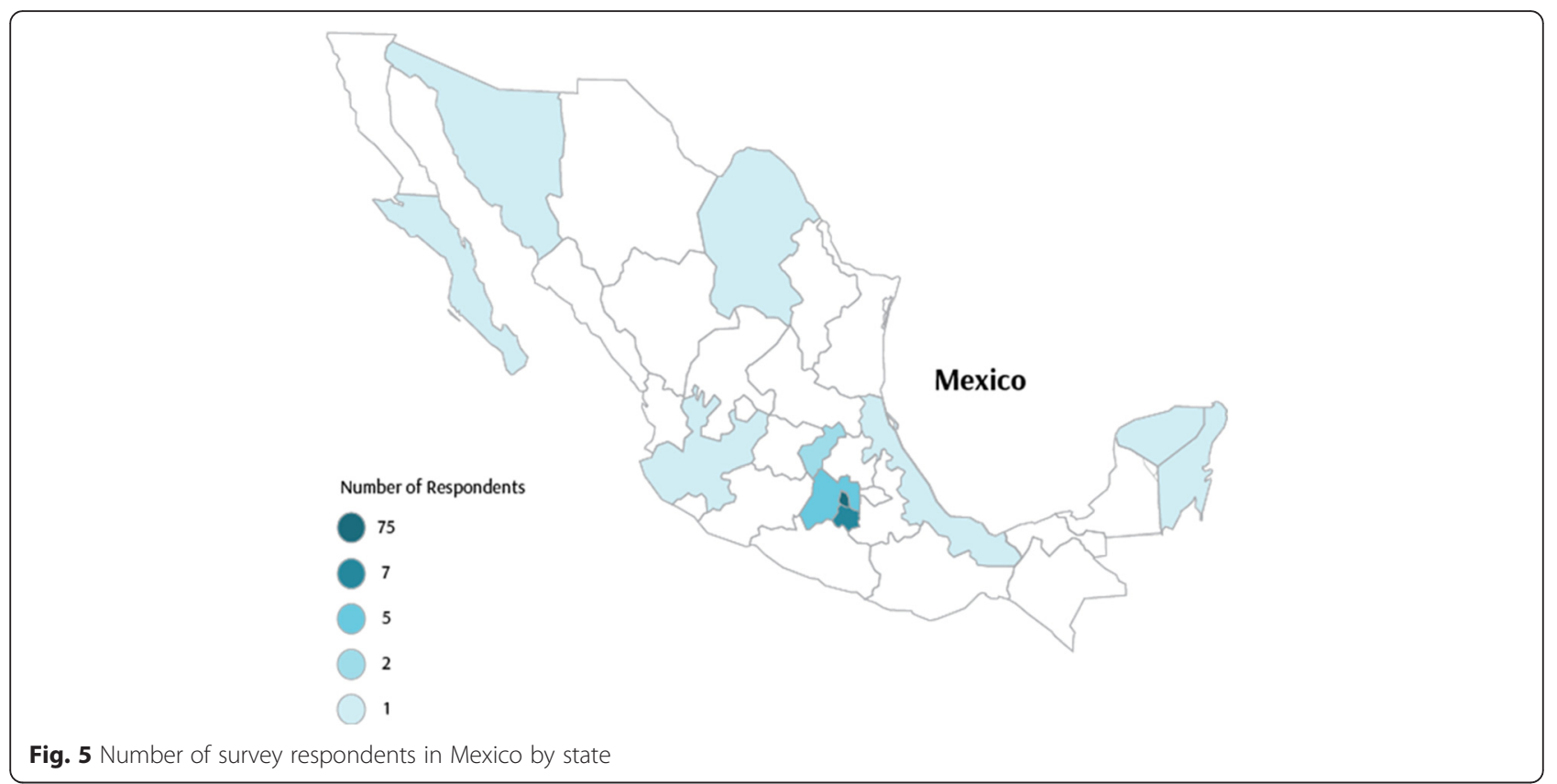

and access to higher education, as well as having the basic resources and commodities.

The level of customer perceptions and awareness of textile recycling and reusing (secondhand stores, charity, upcycling, etc.)

It is found in Fig. 7 that most of the respondents understand that sustainable consumption practices involve the actions or activities that makes reasonable use of resources with minimal waste production and that, equally, are economically profitable. These descriptions in general match with the definition of sustainable practices as the activities that meet human needs while preserving the environment so that these needs can be met not only in the present but also for generations to come, as specified in Our Common Future, report by the World Commission on Environment and Development (WECD 1987).

More than $85 \%$ indicated that they felt it was important for companies to be worried/concerned about the adoption of sustainable practices, inferring that the concern by these companies somehow transfers as a concern for consumers. These big companies are arguably the greatest generators of waste and deployment of resources.

Most of the respondents show concern about the sustainable consumption behaviour. Around $65 \%$ make a purchase decision while aware of the company's compromise with the environment and $60 \%$ aware of the working conditions of the company's employees. More than $71 \%$ consider it useful to be informed on the issues related to sustainable practices for the daily activities, and this means that most of the interviewees lack understanding in the sustainable consumption practices and are unaware of activities to help this matter.

Comparing the number of vintage stores in Mexico's main cities and metropolitan areas with those in developed countries such as the UK, Spain, or USA, it could be said that this type of business is still growing and it is not as popular as in other countries. Then, it is comprehensible why most of the respondents did not have an idea of the difference between vintage and secondhand clothing. The perception of buying pre worn clothes is still misunderstood as unsanitary.

Only $16 \%$ of the respondents gave an accurate response of the difference between vintage and secondhand clothing. The rest of them did not know or had a misconception believing that vintage clothes are new with an old style. The most accurate response was the following:

Vintage clothing is one that has more than a decade and have been produced showing classic features of its time. Second hand clothing is clothing that has been used by someone after the person who bought it in the store has stopped using. The vintage clothing is generally all second hand but not all second hand clothing is vintage.

Also, it is important to notice that $37 \%$ of people that claims to have bought vintage clothes before are generally more involved in the subject and are looking for uniqueness and stylish garments that are not on the high street. As shown in Fig. 4, factors such as differentiation and the search of a specific brand have more relevance than the fact that buying vintage clothing is good for the 


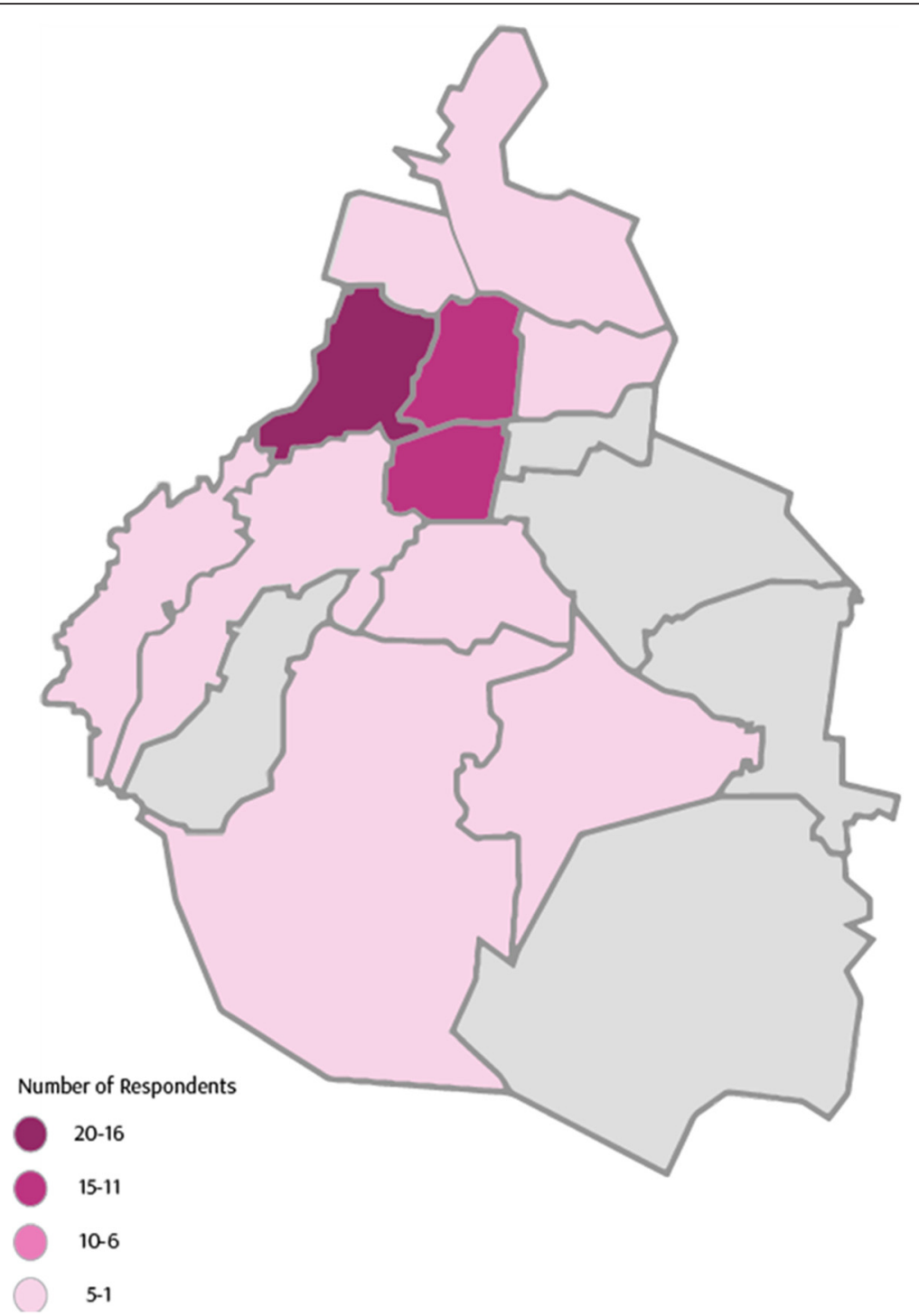

Fig. 6 Number of survey respondents in Mexico City by district

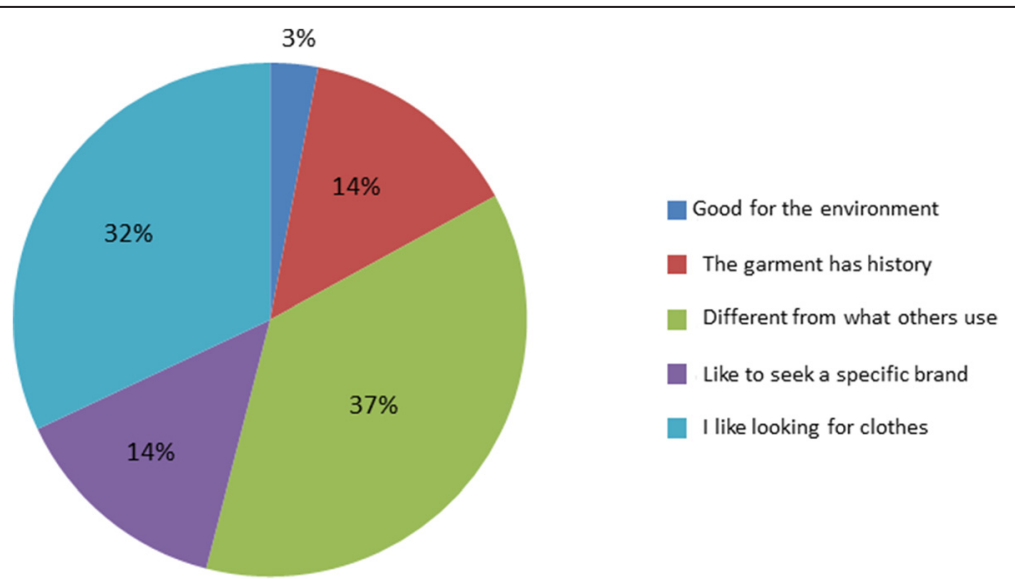

Fig. 7 Main factors considered for making purchase of vintage clothing 
environment. This is an opportunity to communicate to the consumer about the benefits that would come when buying secondhand clothes, such as exclusivity and lower costs.

The main reason for $51 \%$ of the audiences has never bought a vintage garment (see Fig. 8) is that they have never been to a vintage store, and $21 \%$ of them do not like the idea of wearing a garment that has already been used.

It was shown in the results that a proportion of $33 \%$ of respondents have the experience of purchasing ecofriendly garment(s) before. This percentage shows the low penetration that sustainable clothing has had in this audience, and it represents an opportunity to exploit a market that is concerned about the environment but has very few options to choose from. However, when further investigating the reasons why people made the purchasing of eco-friendly garment(s) (see Fig. 9), it is found that only $37 \%$ of such purchases (i.e. only $12 \%$ of total respondents) are driven with an environmental friendly awareness, the rest of the driving force of the rest of purchasing is due to fashionable factors (e.g. style, colour and quality). Therefore, there is large room for educating consumers on the eco-friendly awareness and behaviour.

\section{Customer disposal behaviours and consumption patterns with textile wastes}

When asking about clothing disposal habits, more than half of the respondents answered that they clean their closet more than once a year and when they do this, most of them take the clothes to charity or give them to a friend or familiar who can reuse them. It is also important to notice that most of the people that donate to charity take the clothes to orphanages, domestic employees or homeless people in the street and most of them take the clothes personally to these places or to these people. Is clear that more than half of the respondents are worried about where to take clothes for a closed loop life, but it could be difficult and time consuming to look for a place or person that takes them.

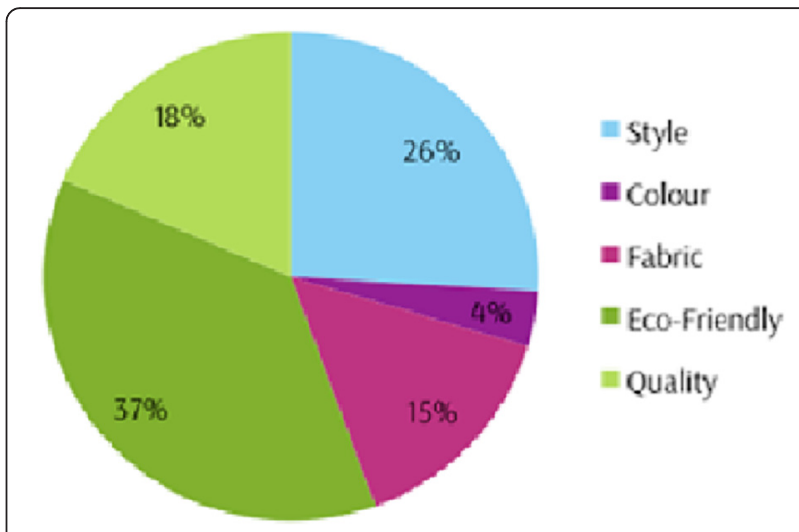

Fig. 9 Reasons for purchasing eco-friendly clothing

In terms of consumption behaviour (see Fig. 10), the three main factors that the respondents think are essential to take into consideration while buying new clothes in order of importance are price, quality and style or design. Not surprisingly, only $5.3 \%$ chose the environmentally friendly factor as one of the main three and only $4.4 \%$ seem to care about fair trade practices. Additionally, when asked if they consider the consequences of their purchase on the environment, only $21.1 \%$ answered they did. Apparently, most of the respondents are not aware of the impact of garment production and the waste of resources that this implies, not even if the garment ends up in the landfill and the consequences of this happening.

It appears contradictory that $85 \%$ of the respondents think that clothing companies should worry about developing sustainable practices, but when asked if they think about the consequences of their purchases, almost $80 \%$ of people said that they do not take in consideration the effects in the environment. It can be implied that the concern for the environment is generally left for government and companies as part of their social responsibilities, as they are big corporations and they should be the ones in charge of caring for these matters.
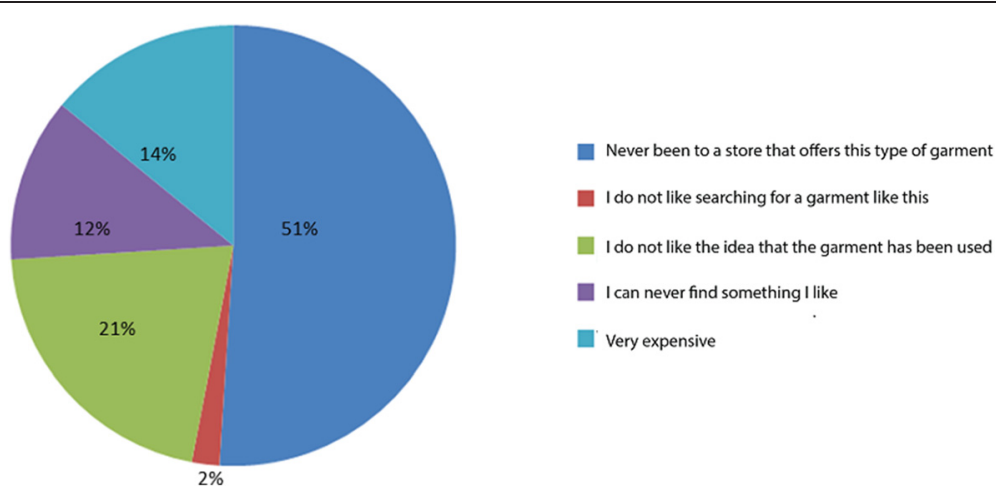

Fig. 8 Factors considered for not purchasing vintage clothing 


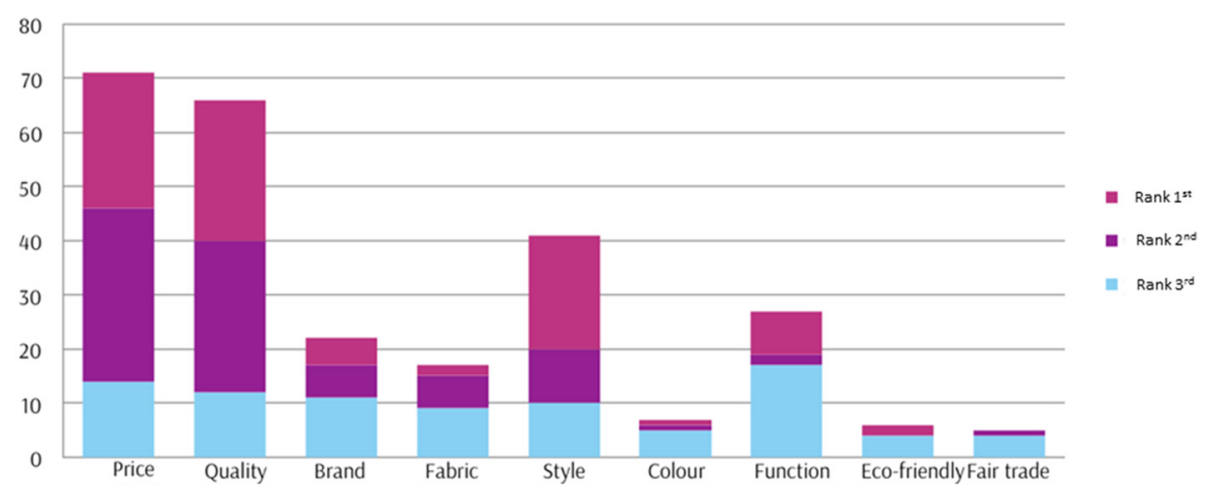

Fig. 10 Three main factors in consideration when purchasing new clothes

\section{Willingness to engage in recycling activities}

It is found that $96 \%$ of respondents have either a very strong or strong interest in the care of the environment. Apparently, the consumers are aware that there are actions to be taken, and this data matches with the survey done in 2011 by INEGI where it was shown that $85.8 \%$ of the interviewees between 18 and 65 years old were concerned about different topics affecting the environment they lived in, showing that all of these respondents have been affected at least by one problem such as air pollution, excessive traffic or garbage in the streets. It is noticed in INEGI's research (INEGI 2013) that only $35 \%$ actively participate in activities to care of the environment and $57 \%$ of them know the consequences of climate change, this might be due to the fact that $58 \%$ of their interviewees only have basic or none education at all. In our research, it is found that $73 \%$ of the respondents take sustainable actions to preserve natural resources and to avoid waste of energy and they mainly recycle or reuse the waste paper, plastic and clothes in their home and office. The main reasons for those who do not recycle are the lack of information of recycling culture, followed by absence of containers and lack of time. One respondent mentioned that economic benefits are the main motivations for him/her to take any sustainable actions. Apparently, there is a niche of a younger audience that seeks rewards or added value in their buying and by all means would not be motivated to pay more to be a sustainable consumer.

In order to identify the recycling habits and use of bins, the respondents were asked about the availability and use of recycling containers near their house and office/school. It is found that more than $78 \%$ of the respondents believe there are not enough bins near their house, and $62.6 \%$ believe that there are not enough bins near their school or office. When asked if they use the bins available, more than $68 \%$ said that they have used or would use them, but in general terms, more than half of the respondents think that it is either hard or slightly hard to take the waste to these containers, most probably because of the distance to reach them or the conditions of those containers.

\section{Willingness to collaborate with brands}

To identify the willingness of the audience to different sustainable products, there were different questions concerning diverse products that involved recycling of textiles and garments (see Fig. 11). When asked if they would buy a product made from recycled fabrics, the answer was really positive. Additionally, the answer was

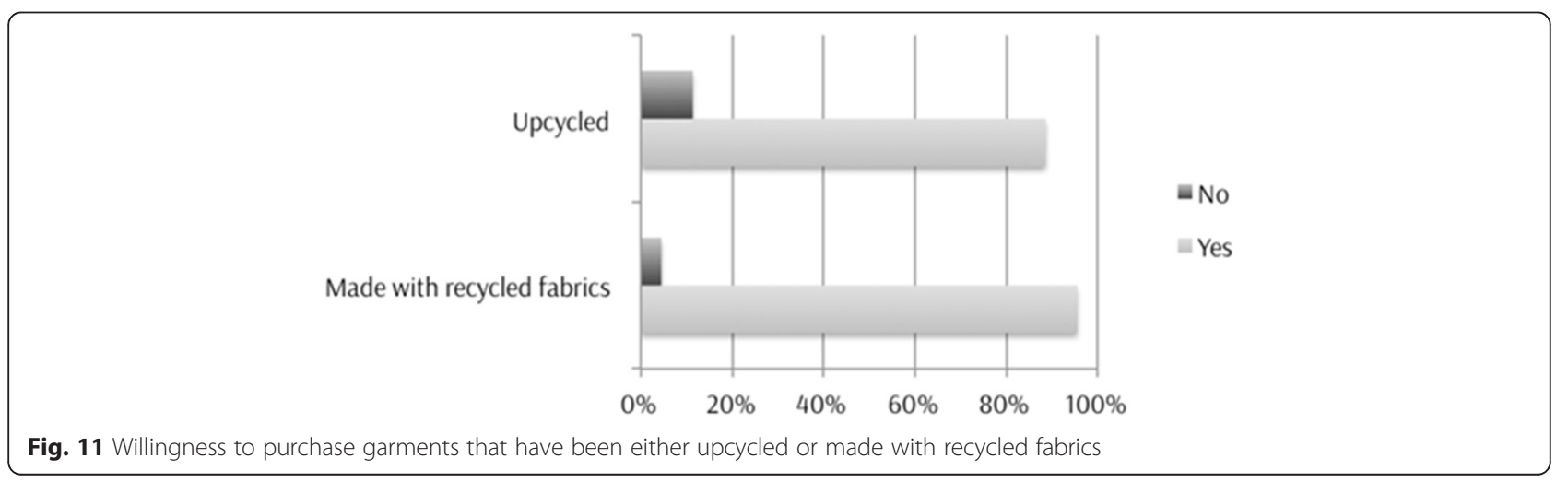


quite similar when asking if they would buy a product that has been upcycled with the use of several secondhand garments, with the factor of design being the main reason for their purchase followed by sustainability with $29 \%$ of the answers.

In terms of participation of the target audience in the collection of garments for recycling (see Fig. 12), the level of willingness to take the garments to a collection centre is quite high with $59.1 \%$ of the respondents being totally willing to participate if this means that they would be helping the environment or a low-income community for sustenance and $39.8 \%$ being really motivated if that means getting a discount for a future purchase.

Furthermore, respondents where less excited about buying clothes made only from secondhand clothes and even less motivated to pay more for the garments even if this means that they would be helping to work in fair and healthy working conditions and the preservation of the environment.

(Note: In $Y$-axis, 10 is the greatest willingness to support various sustainable activities and 0 is the least willingness to support various sustainable activities.)

\section{Evaluation of this pilot study}

Although collecting data from a much larger cohort would be desirable in the first instance, this pilot study involved a comparatively small number of participants.
However, the relatively smaller sampling size do not affect the reliability of the conclusions drawn from this research as explained in the section of "Research methodology", and this might also lay down a solid basis and guide for the future full scale of investigation and their survey design. All of the indicators from this pilot study give a good degree of confidence in terms of extending the study.

It is evident that there is positive attitudinal inclination among the selected demographic of willingness to be actively involved in some aspect(s) of ethical consumption. The data collected from the demographic cohort involved in this research, who have indicated both awareness and willingness to be part of a shift to more ethical consumption, seems both justifiable and appropriate given their increase in disposable income and disposition to spend this disposable income on fast fashion and textile goods. There are some indications that the targeted demographic demonstrate inclination to help but are unaware of the options available and in place within specified cities and regions of Mexico. Extending the study to examine the target demographics' actions in terms of providing trial options of a variety of disposal activities of their textile and fast fashion waste could help determine a viable option moving forward. In addition, a longitudinal study to test a range of educational strategies about the issues of ethical consumption and disposal of textiles seems worthy of further study.

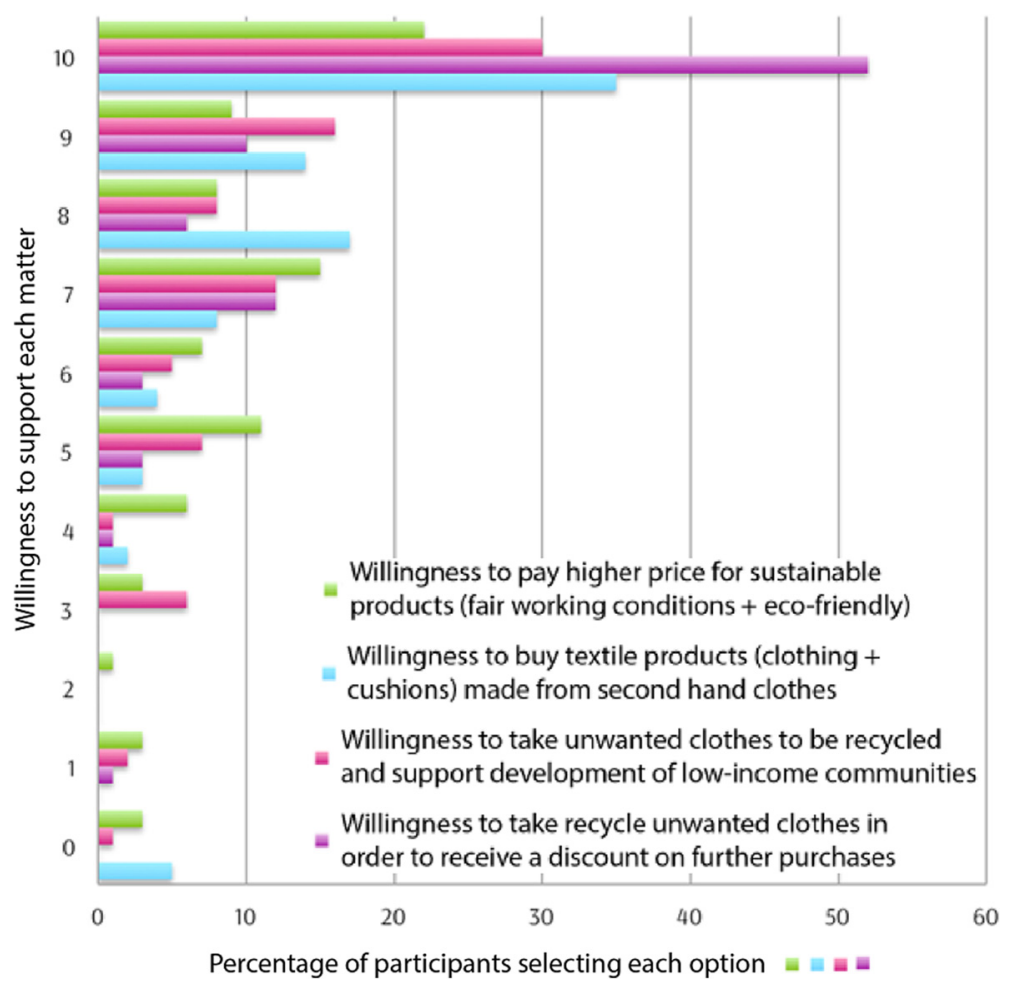

Fig. 12 Willingness to support different sustainable activities 
It is arguably not an easy job to extend the benefits of ethical consumption as broad as demographic as possible, given that a cultural shift is somewhat challenging, especially in conservative countries that take a while to embrace change including governmental interrogation on the scope of issues raised and their willingness to be part of the ideas expressed in this study also merit further study and enquiry.

This is in power of the government, profit and nonprofit organizations, new designers and entrepreneurs to offer a collective set of sustainable alternatives with different propositions that would attract all segments of the population to contribute. Either to purchase products or dispose them at the end of their use, consumers need a variety of options to choose from. Furthering the study to investigate a range of options for the disposal and end of use of textile products is both worthy of further study, and Mexico as a growing economy seems suited as a context for further exploration. Therefore, measures are suggested in the next section to develop ethical consumption of textiles in Mexico.

\section{Suggested measures to develop ethical consumption of textiles in Mexico}

In the analysis above, there were two results drawn especially important that means an opportunity of entrance for the organization in question. First, the consumer's interest in the environment is clearly high, even though some respondents are understanding about the matter and may only look for economic benefits. Additionally, it was found that the environmental education is still quite poor and there is still little communication from the government or any other organization about textile waste recycling. Furthermore, there is not enough containers or collecting points for these; hence, people find it quite difficult to get rid of waste that could be reused.

The second opportunity shown by this questionnaire is the fact that people have a clear interest in ethical consumption, but the lack of information about the benefits and scarcity of alternatives for sustainable brands and initiatives make the intention of sustainability quite exhausting and time consuming. The apparent gap in the market shows that a clear communication is essential to trigger ethical consumption. The brand, in this case as a non-profit organization, would need to communicate to and in some way educate the audience in order to create awareness about the problem ahead and emphasize the benefits that would come with it, either economically or for self-invigoration.

During the last 6 years of government, there have been continuous activities and campaigns regarding the reduction of emissions of gas and waste separation and management (SMA 2012b). Even though, there has not been a specific action for textile waste management, hence, there is no-recycling programme for postconsumer or post-production textile waste. It is important to tell people the opportunities they have to discard their clothes, as well as to promote the recycling of different types of waste for use in new fabrics among the industry.

Hawley and Fletcher proposed that the challenge towards sustainability in the textile industry is to expand the limits of change from focusing on niches into developing a system that tackles environmental matters in a parallel interaction with social and economic concerns (in Gwilt and Rissanen 2011). This way of thinking applied to an organizational framework would be able to evoke a constant and permanent change in the textile consumption and discarding patterns; leading to a whole cycle of activities that mean a potential change for good in the textile industry while benefiting all its stakeholders.

It is identified in the survey that, as a result of the change in apparel consumption patterns and the growth of the turnover of clothing, the textile recycling culture in developing countries needs to be strengthened in order to promote reuse of textile waste. Arguably, there should be a constant garment collection culture, which will be the main resource for developing any activity that involves textile reusing and recycling. These will help:

- Trigger the awareness of the impact of textile waste on the environment

- Communicate and develop sustainable activities and practices in the society

- Change the consumers' perceptions and attitudes towards mass consumption

- Evoke a textile recycling behaviour and culture

- Benefit all strata of society

A good strategy for more efficient textile waste processing might be helpful to achieve this, and an example of such textile waste processing system is proposed as shown in Fig. 13. In this textile waste processing system, there are two aspects worth of paying close attention at: marketing strategy for sustainable activity programmes and target audience and stakeholders. They are discussed in details in the next section.

\section{Marketing strategy for sustainable activity programmes}

As a green brand trying to successfully gain brand equity, it is important to establish a corporate brand personality that exposes three dimensional values: heart, body and mind. Characteristics as passion, compassion, creativity, discipline, agility and collaboration are fundamental as brand personality traits in order to gain and maintain the desire brand image and afford to change consumer's perspective about sustainability (Keller and Richey 2006). 


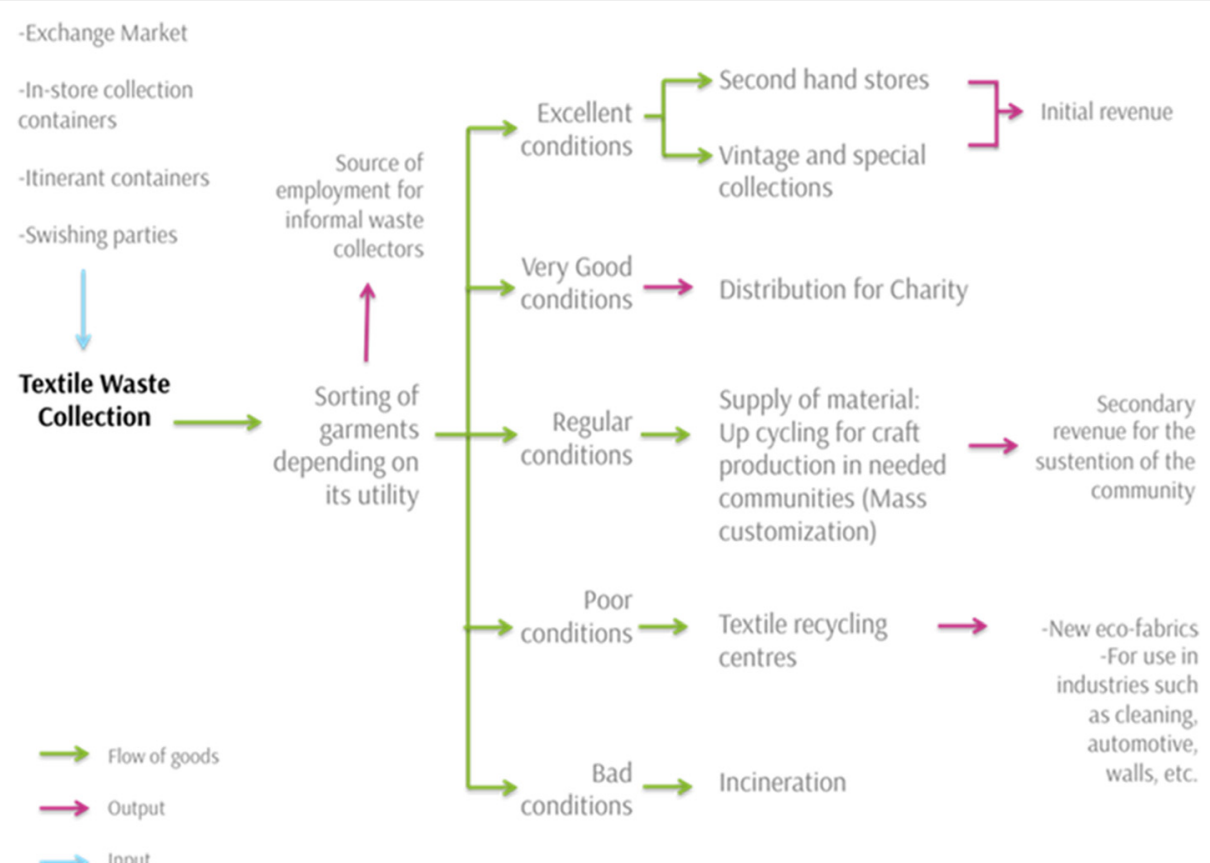

Fig. 13 Proposed strategy of textile waste processing system

Furthermore, the eco-textile market is constantly affected by consumers' attitudes that associate them with negative associations; thus, it is important to reduce this prejudgements and to develop a positive attitude towards green textiles with the proper use of branding that includes a clear informational process where the customers are aware of the origin and procedures that took to manufacture a sustainable product (Lorek and Lucas 2003).

It is essential to communicate a brand personality that stands for changing the way the regular brands talk to the audience by promoting a conscious lifestyle instead of compulsive consumption behaviour. Additionally, an educational communication campaign that intents to promote the culture of recycling will allow changing the perspectives of the stakeholders in the search for reducing the volume of textile waste.

According to Green and Peloza (2011), there are three different approaches to creating brand values for the customer with the use of CSR: emotional, social and functional. These values will be the drivers to create a purchase decision, either by themselves or combined and the level of importance would change depending on the environment and background of the customer. In this research, it was also found that the functional values of a sustainable product are still in top of the mind of the socially responsible customer, especially in difficult economic times, followed by emotional and social values that will be achieved by intangible assets that will provide sense of goodwill and social acceptance (Green and Peloza 2011).
The marketing strategy for any sustainable company or organization that wants to trigger sustainable lifestyles, in general, needs to focus on influencing social behaviours to benefit the target audience and the general society (Madill and Ziegler 2012). In response to the findings from this study, the objective of the branding process is to develop a social responsible corporate brand whose main purpose/goal is the collection of post-consumer garments or textiles to give them a new life. By recycling, reusing or upcycling the garment, the organization's main purpose would be to add value and lifetime to every textile product recollected. The benefits provided to the different stakeholders would be vast, as well as the main help to the environment preserve. Furthermore, this initiative also supports the lower social class through providing opportunities to acquire skills and make profits for economic support of the family.

The establishment and development of the brand will involve the cooperation and mutual understanding of the current governmental activities, such as 'The Green Plan' (Plan Verde) and 'Tu Ola' programme, in order to obtain the textile waste with the use of collecting initiatives as well as up keeping the recycling culture. These organizations have recently established the parameters for waste exchange and reward programmes that encourage citizens to participate by separating their waste and delivering it in the monthly market that collects it.

With the ideal communication tools and approach to the desired target markets, the customer will understand the value of helping with the preservation of the 
environment and of supporting vulnerable communities to increase their income and quality of life (Lefebvre 2009).

\section{Target audience and stakeholders}

A non-profit organisation that performs in a continuous flow of goods would eventually need to reach and persuade very different audiences, from donors, volunteers, buyers, switchers and investors to craft communities or other communities that would benefit from the profits made. This entire group needs a different approach to communicate to their stakeholders. It all begins with the donors of clothing and textiles. As previously discussed, the group that would make a substantial impact for this cause are the young affluent consumer, who has the potential to be the biggest consumer from the more affluent strata of the society. This group is also usually sensitive to ethical issues (Horne and Maddrell 2002), so it is important to communicate a clear message to them, trying to use the most common touch points to reach them, such as social media, websites, online shops and public events.

\section{Possible brand extensions}

Brand extensions are well tested in many market sectors and with these successes in mind, it would be certainly worthy of some trials being conducted in terms of the addition of textiles being added to these brand successes. The participants were questioned about this new textile brand being an extension of the currently successful initiative for the itinerant exchange market (Mercado de Trueque) and the Tu Ola initiative which has the advantage of government support. The survey results indicated that the targeted classes of participants would be open to a new reused/recycled and upcycled brand that deals with textile products.

\section{Conclusions}

A significant majority ( $85 \%$ ) of the participants in this pilot study indicated that they felt it was important for companies to be worried/concerned about the adoption of sustainable practices. In addition, the majority (65\%) of the participants indicated concern about their own consumption behaviour in regards to textile products. The majority $(71 \%)$ also indicated that being better informed about the issues of sustainable practices in daily activities as a means of assisting better understanding about how to behave in a more ethical manner regarding both the consumption and end of life cycle of textiles goods. These responses can be deemed as indicators that there is potential scope to extend this study with the aim of introducing some form of textile recycling system in Mexico. Further study with more participants could also be used to determine whether Mexican's with the classifications used in this pilot study would be more open to the development of a new and original style of recycling initiative or to build and extend upon an existing system or links to recycling systems already used in this country.

The study indicates that there is definitely a growth in the economy in Mexico. The main positive impacts of the growth in the economy are those with a university education. These graduates are mainly living in Mexico City. These prosperous graduates will be likely to follow their counterparts in previous growing economies such as those from China and India. If this is true, there is a good indication that they will spend a significant amount of their wages on clothing and textiles for the home. There are other indicators that this group of younger consumers is also interested in sustainability issues and consumption.

The survey findings from this study indicate that a majority percentage of the respondents find that the convenience of the current location of waste textile bins do not make it easy and convenient to undertake the recycling of textiles and clothing. This is in spite of the participants having a high level of inclination to undertake this conscientious activity.

There is some degree of evidence from this study to indicate that the offer of some discount incentive when making a purchase of clothing and textile products would occur if a donation of clothing and textiles that are no longer required. This evidence would require further probing and investigation in order for this information to be regarded as useful and conclusive in retail stores taking this on board as part of their ongoing sustainability strategy.

Finally, education could be arguably at the centre of the findings of the study. Training of people to create desirable reused clothing suits a market demand in terms of style and taste. Educating the rising number of economically advancing people in Mexico about the benefits could occur if a premium was charged for environmentally conscious clothing and textile products and of fair trade issues in farming, manufacture and business such as retailers.

An attempt to create and develop a new textile disposal and buying behaviour is arguably a difficult matter.

\section{Additional file}

Additional file 1: Market research survey questionnaire for this pilot study.

Competing interests

The authors declare that they have no competing interests.

Author's contribution

TCD, BC and NM participated in designing and coordinating the study and drafting the manuscript; TCD implemented the research and drafted the 
manuscript; BC and NM directed the strategy of the research, structured this paper and helped the analysis and discussions and drawn conclusions. All authors read and approved the final manuscript.

Received: 18 November 2015 Accepted: 27 March 2016

Published online: 26 April 2016

\section{References}

AMAI (2004) [Online] Accessed 20 June 2013

AMAl (2005) [Online] Accessed 20 June 2013

Corral-Verdugo, V. (1996). A structural model of reuse and recycling in Mexico. Environment and Behavior, 28, 665.

Draggan, S., \& Saundry, P. (2012). "Mexico". In C. J. Cleveland (Ed.), Encyclopedia of Earth. Washington, D.C.: Environmental Information Coalition, National Council for Science and the Environment.

Euromonitor (2013). Apparel and Footwear in Mexico: industry overview. Euromonitor International [Online]. April 2013. Available at: https://www. portal.euromonitor.com/. Accessed 18 Apr 2016.

Gillham, B. (2000). Developing a questionnaire. London: Continuum.

Green, T., \& Peloza, J. (2011). How does corporate social responsibility create value for consumers? Journal of Consumer Marketing, 28(1), 48-56.

Gwilt, A., \& Rissanen, T. (2011). Shaping sustainable fashion: changing the way we make and use clothes. London: Earthscan.

Horne, S., \& Maddrell, A. (2002). Charity shops: retailing, consumption and society. London: Routledge, Taylor and Francis Group.

Humphery, K. (2011). In Lewis \& Potter (Ed.), The simple and the good: ethical consumption as anti-consumerism (pp. 40-53).

INEGI. (2013). Mexico in numbers. [Online] Available at: http://www.inegi.org.mx/. Accessed 18 Apr 2016.

Keller, K. L., \& Richey, K. (2006). The importance of corporate brand personality traits to a successful 21st century business. Journal of Brand Management, 14(1), 74-81.

Las Páginas Verdes (The Green Pages) (2012). ¿Quiénes somos? (Who we are?) [Online]. Available at: http://laspaginasverdes.com/. Accessed 18 Apr 2016.

Lefebvre, R. C. (2009). The change we need: new ways of thinking about social issues. Social Marketing Quarterly, 15, 142.

Littler, J. (2009). Radical consumption: shopping for change in contemporary culture. Berkshire, UK: Open University Press.

López Romo, H. (2009). AMAl Advances: Distribution of Socioeconomic Levels in Urban Mexico. Social Investigations Institute, S.C. [Online]. Available at: https:// www.canback.com/amai_mex_sel.pdf. Accessed 18 Apr 2016.

Lorek, S. \& R. Lucas, (2003). Towards sustainable market strategies: a case study on ecotextiles and green power [Online]. Wuppertal Institute for Climate, Environment and Energy. Available at: https://epub.wupperinst.org/frontdoor/index/index/ docld/1734. Accessed 18 Apr 2016.

Madill, J., \& Ziegler, R. (2012). Marketing social missions-adopting social marketing for social entrepreneurship? A conceptual analysis and case study. International Journal of Nonprofit and Voluntary Sector Marketing, 17(4), 341-351.

Mattos, M. (2012). Sustainable Brazil: perceptions and practices of the new Brazilian middle class on sustainability and conscious consumption. GfK CR, Brazil. May 2012. Available at: https://www.esomar.org/web/research_papers/OpinionPolling_2367_Sustainable-Brazil.php. Accessed 18 Apr 2016.

Miaoulis, G., \& Michener, R. D. (1976). An introduction to sampling. Dubuque, lowa: Kendall/Hunt Publishing Company.

Morgan, L. R., \& Birtwistle, G. (2009). An investigation of young fashion consumers' disposal habits. International Journal of Consumer Studies, 33(2), 190-198.

Schwab, K. \& Sala-i-Martin, X. (2012). The global competitiveness report 2012-2013. World Economic Forum [Online]. Available at: http://www3.weforum.org/docs/ WEF_GlobalCompetitivenessReport_2012-13.pdf. Accessed 18 Apr 2016.

SEMARNAT. (2012). Residuos. México. [Online] Available at: http://www.sedema.df. gob.mx/sedema/index.php/temas-ambientales/programas-generales/ residuos-solidos. Accessed 18 Apr 2016.

SMA (2012a). ¿Qué es el Mercado de Trueque (What is the Exchange Market?). September 2012. [Online] Available at: http://sedema.df.gob.mx/ mercadodetrueque/index.php?option=com_content\&view=article\&id= 50\&ltemid=29. Accessed 18 Apr 2016.
SMA (2012b). Plan Verde Ciudad de México: 5 años de avances (Mexico City's Green Plan: 5 years of advances). September 2012. [Online] Available at: http://www. planverde.df.gob.mx/ecotips/73-miscelanea/694-2012-11-30-23-04-26.html. Accessed 18 Apr 2016.

Truett, L. J., \& Truett, B. (2010). Globalization challenges for the Mexican textile industry. International Review of Economics and Finance [Online], 19(4), 733-741. doi:10.1016/j.iref.2010.04.003.

Tu Ola: el 1er programa en México que te recompensa por cuidar el medio ambiente, [Online] Available at http://www.swagger.mx/tecnologia/tu-ola-el1er-programa-en-mexico-que-te-recompensa-por-cuidar-el-medio-ambiente. Accessed 18 Apr 2016.

WBCSD (2008). Sustainable consumption facts \& trends from a business perspective. Geneva, World Business Council for Sustainable Development [Online]. Available at: http://www.wbcsd.org/pages/edocument/edocumentdetails. aspx?id=142. Accessed 18 Apr 2016.

WECD (1987) [online] www.un-documents.net/wced-ocf.htm. Accessed 18 Apr 2016.

\section{Submit your manuscript to a SpringerOpen ${ }^{\circ}$ journal and benefit from:}

- Convenient online submission

Rigorous peer review

- Immediate publication on acceptance

- Open access: articles freely available online

- High visibility within the field

Retaining the copyright to your article

Submit your next manuscript at $\boldsymbol{s p r i n g e r o p e n . c o m ~}$ 